Supplementary information

\title{
Construction of Dual-Color Probes with Target-Triggered Signal Amplification for In Situ Single-Molecule Imaging of MicroRNA
}

Binxiao Li, Yujie Liu, Yixin Liu, Tongtong Tian, Beibei Yang, Xuedong Huang, Jianwei Liu*, and Baohong Liu*

Department of Chemistry, Shanghai Stomatological Hospital, State Key

Laboratory of Molecular Engineering of Polymers and Institute of Biomedical

Sciences, Fudan University, Shanghai 200433, People's Republic of China

${ }^{*}$ Corresponding Author

*E-mail: bhliu@fudan.edu.cn. Fax: +86-21-65641740

*E-mail: jianweiliu@fudan.edu.cn. 


\section{Supplementary Methods}

\section{Quantitation of the Capture Probe Strands Assembled on Per AuNP.}

The concentration of the nanoparticle was calculated by the Beer-Lambert Law $(A=\varepsilon \cdot \mathrm{C} \cdot \mathrm{I})$, while their extinction coefficient $(\varepsilon)$ is $2.7 \times 10^{8} \mathrm{~L} \mathrm{~mol}^{-1} \mathrm{~cm}^{-1}$ at $\lambda 524$. After functioned with capture probes, the absorption value of the 524 $\mathrm{nm}$ peak is $\sim 0.28$ (Figure $1 \mathrm{~b}$ ), so the concentration of the nanoprobe is $\sim 1.04$ $\mathrm{nM}$.

Capture probe strands $(\mathrm{H} 1)$ loaded on AuNPs were quantitated according to the previous protocol ${ }^{1-3}$. First, the mercaptoethanol $(\mathrm{ME}$, final concentration $=$ $20 \mathrm{mM}$ ) was added to the nanoprobe solution for complete release of $\mathrm{H} 1$ from the AuNPs. After shaking overnight at room temperature, the solution was centrifuged to separate the released $\mathrm{H} 1$, and the fluorescence of the supernatant was measured by the fluorescence spectrometer. The fluorescence of Cy5-labeled $\mathrm{H} 1$ with a $646 \mathrm{~nm}$ excitation wavelength was 
converted to molar concentrations of $\mathrm{H} 1$ by interpolation from a standard linear calibration curve (Inset of Figure S1a,) that was prepared with known concentrations of $\mathrm{H} 1$ with same ionic strength, $\mathrm{ME}$, and $\mathrm{pH}$ conditions. From the fluorescence intensity $(\sim 463)$ of the supernatant (Figure S1b) and according to the calibration equation: $\mathrm{F}=-18.337+7.439 \times \mathrm{C}_{\mathrm{H}^{1}}(\mathrm{nM})$, the concentration of capture probe strands immobilized on the AuNPs (1.04 nM) was $64.45 \mathrm{nM}$ and the number loaded on each AuNP was calculated to be 62. The average and standard deviation were obtained by 3 parallel experiments in each trial). 

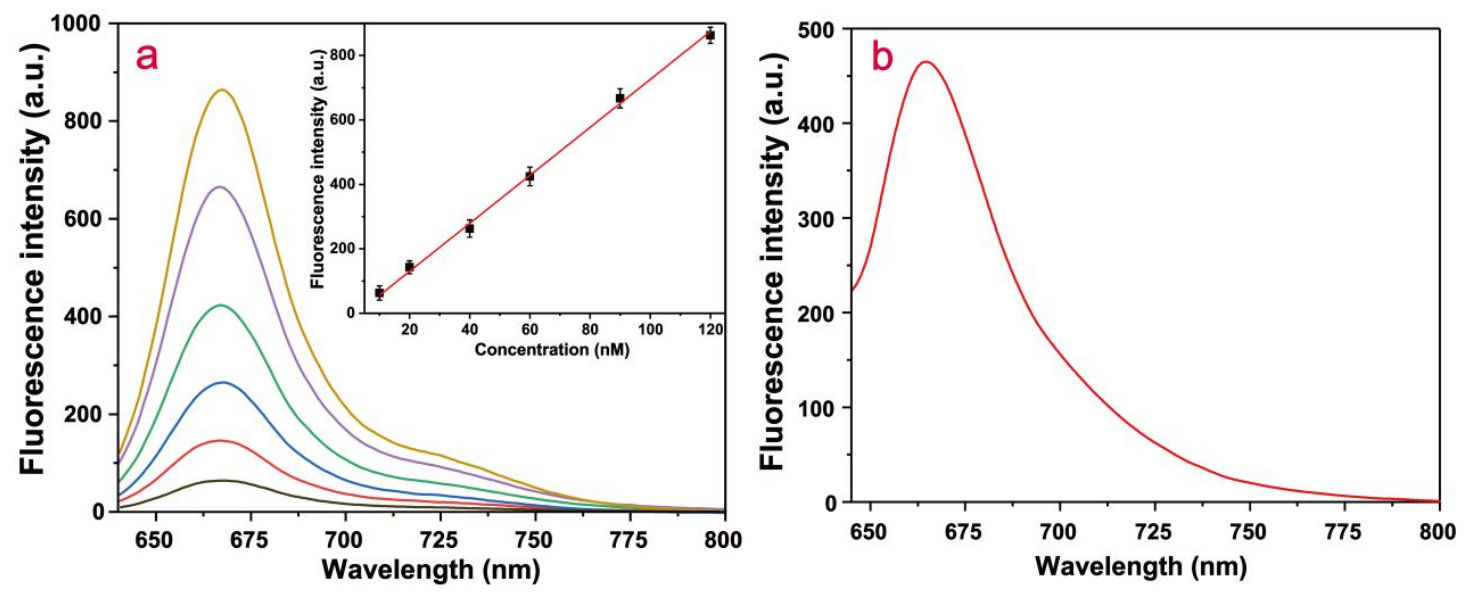

Figure S1. (a) Fluorescence spectra of different concentrations of capture probe strands, the insert curve is the linear relationship between intensity and concentration. (b) Fluorescence emission spectra of the released capture probe strands. Error bars indicate standard deviation of triplicate tests. $(\lambda e x=$ $646 \mathrm{~nm}, \lambda e m=664 \mathrm{~nm})$

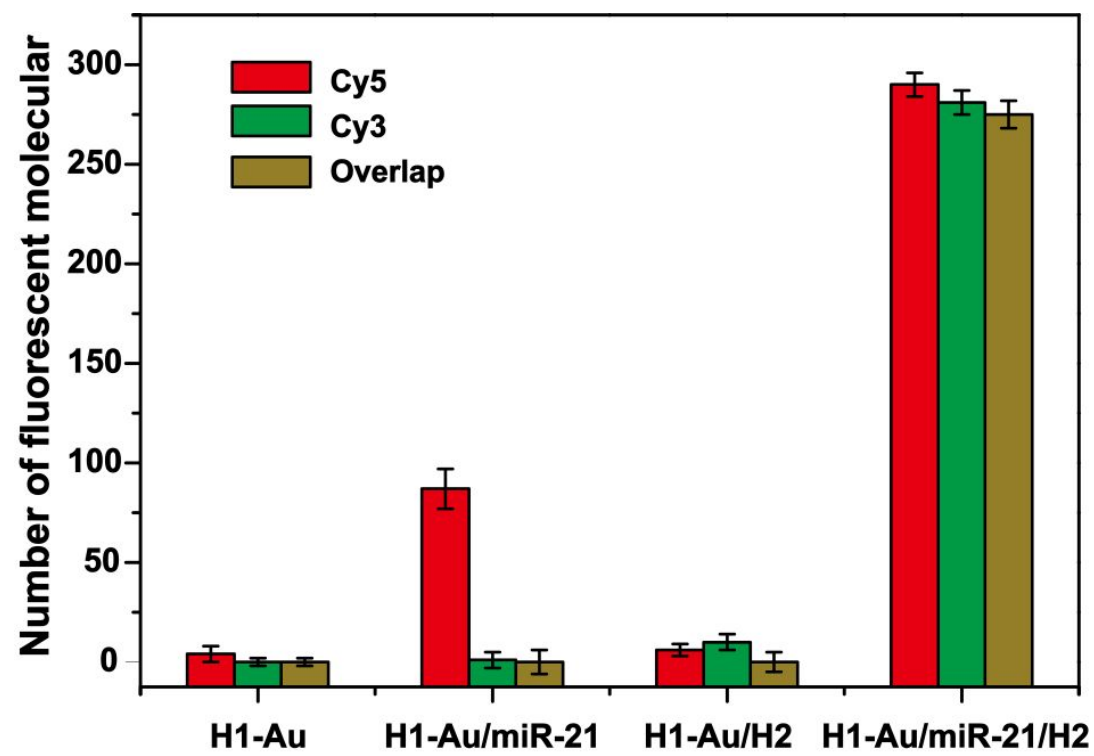


Figure S2. The averaged count numbers of bright spots per image in the absence and in the presence of $\mathrm{H} 2$ or miR-21. Error bars stand for standard deviation of three experiments.

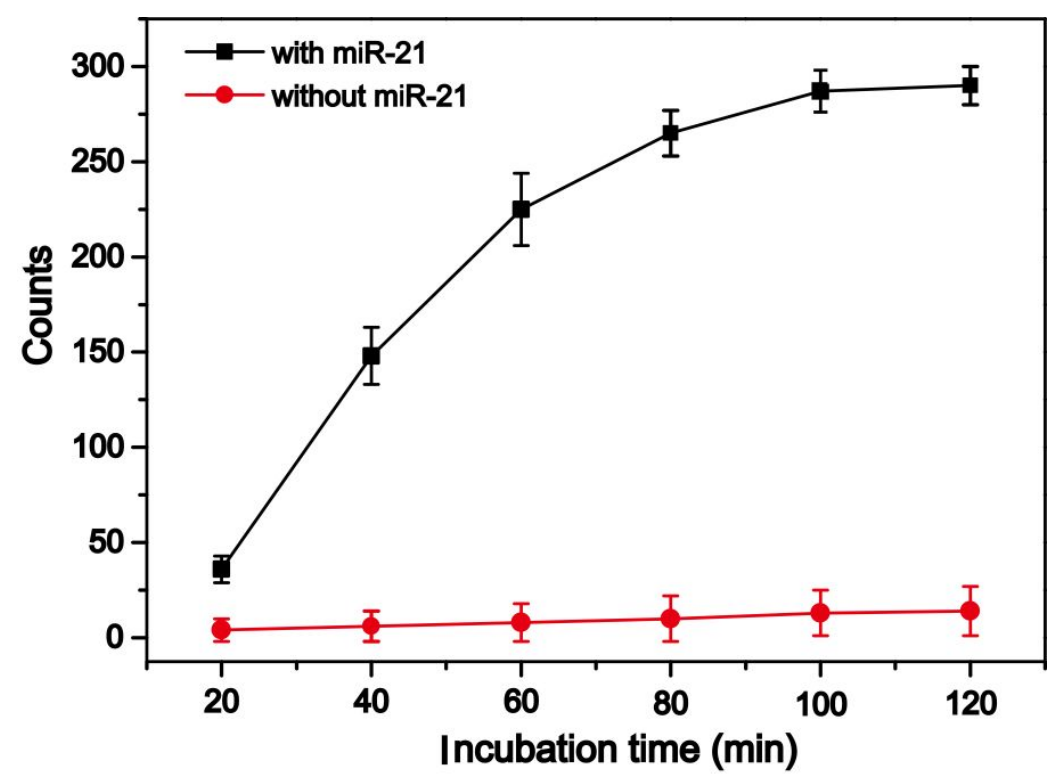

Figure S3. Plot of the averaged count numbers of Cy5 spots per image vs. incubation time. The incubation time in presence and absence of miR-21 (1pM). Error bars stand for standard deviation of three experiments.

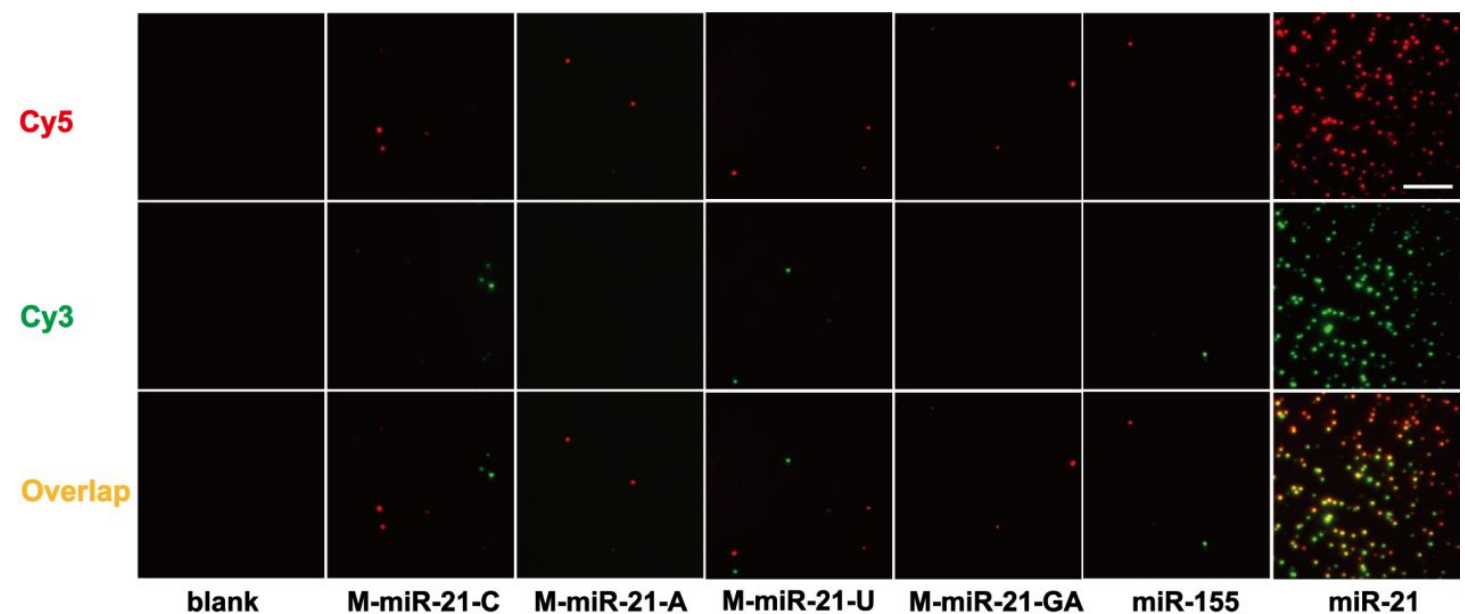


Figure S4. The specificity test of the proposed strategy with single molecule imaging. The scale bar is $5 \mu \mathrm{m}$.
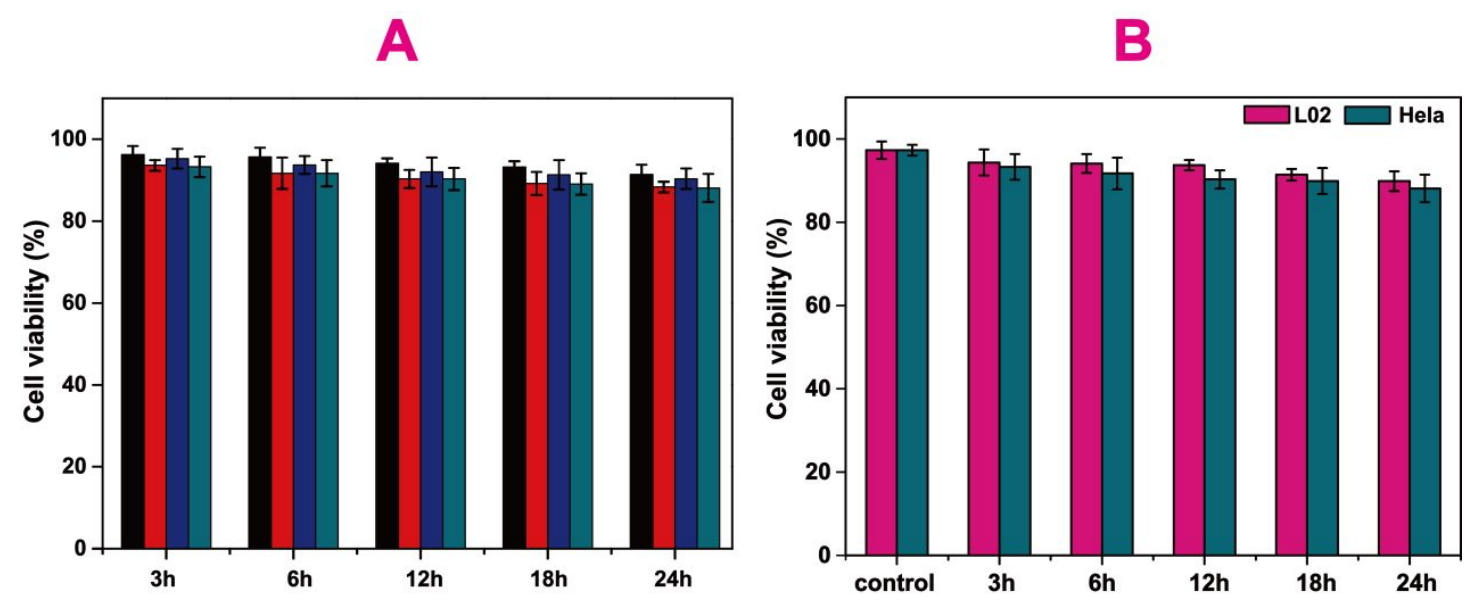

Figure S5. The cytotoxicity experiments of cells. (A)The CCK-8 assays of Hela cells treated with the culture medium (black), PureFectionTM reagent (red), H1-AuNPs (blue), and H1-AuNPs- PureFection/H2 complexes (dark cyan);and (B) CCK-8 assays of Hela cells and L02 cells with H1-AuNPsPureFection/H2 complexes for varying incubation time from 3 to $24 \mathrm{~h}$, respectively, at $37^{\circ} \mathrm{C}$. 


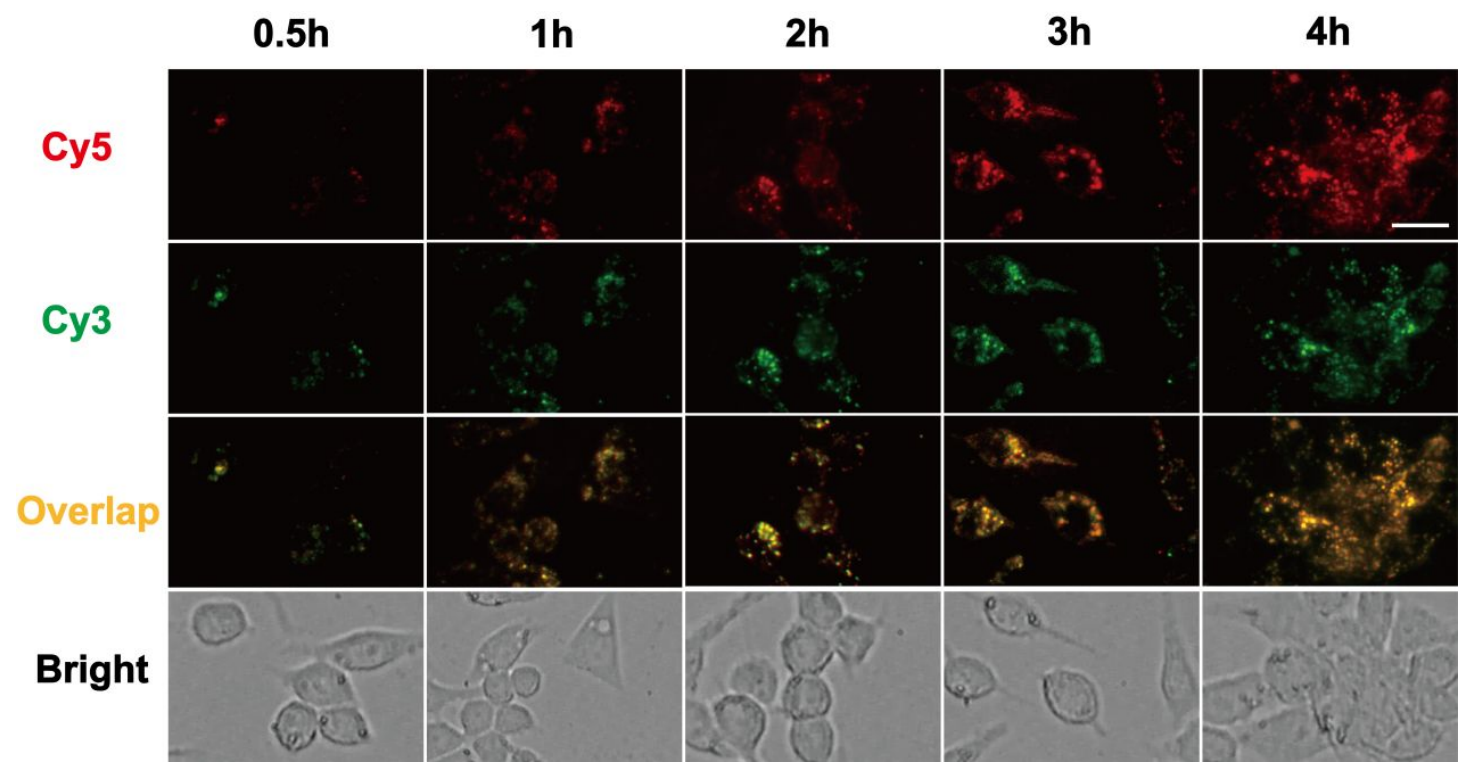

Figure S6. Real-time imaging of miR-21 in Hela cells at different times. The scale bar is $20 \mu \mathrm{m}$.

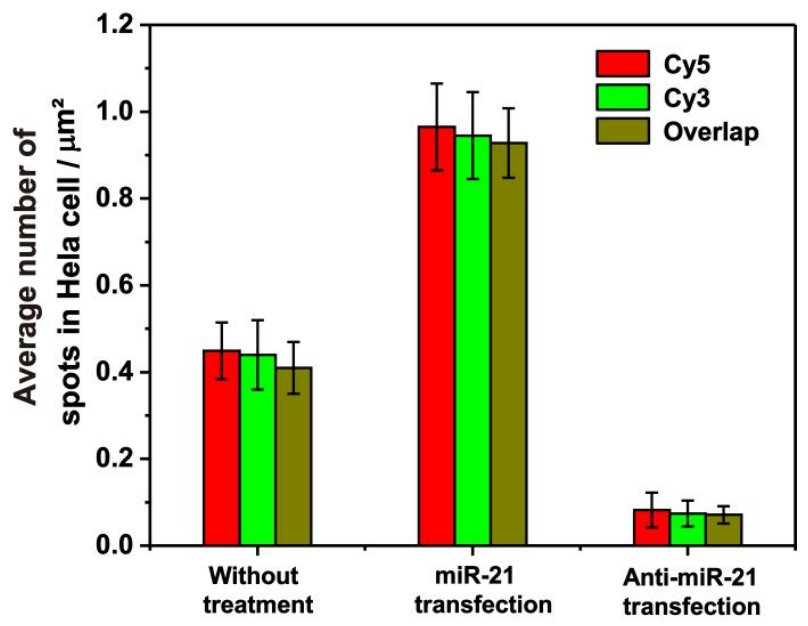

Figure S7. The average number of fluorescent spots per square micrometre in per Hela cell including control group, miR-21-treated group and anti-miR-21-treated group. The error bars represent the 95\% confidence interval obtained by analysis of 20 cells. 


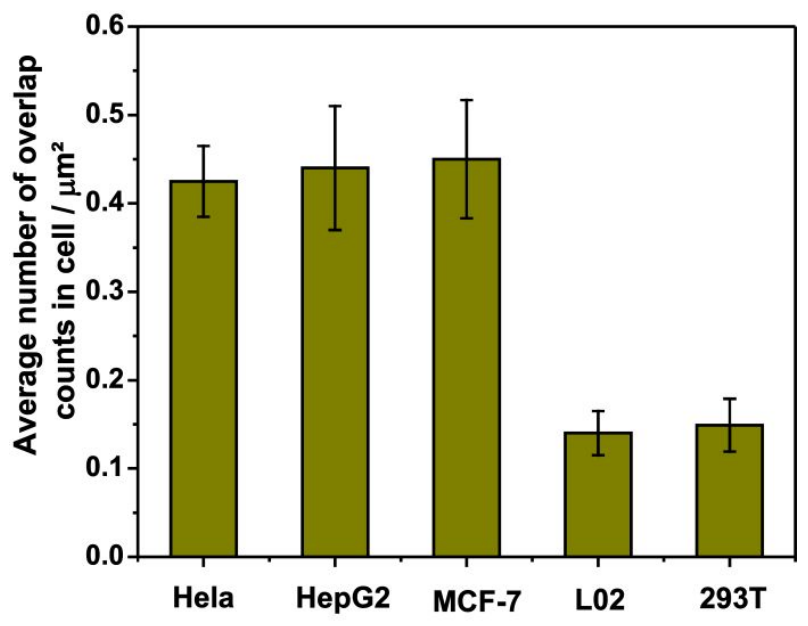

Figure S8. The average number of overlap spots per square micrometre in per cell including Hela, HepG2, MCF-7, L02 and 293T cells. The error bars represent the $95 \%$ confidence interval obtained by analysis of 20 cells.

Table S1. Comparison of the proposed method with the reported methods for miRNA assay.

\begin{tabular}{|l|l|l|l|l|}
\hline method & ensemble & valid signal & detection & ref. \\
\hline
\end{tabular}




\begin{tabular}{|c|c|c|c|c|}
\hline & signals & & limit & \\
\hline $\begin{array}{l}\text { fluorescent assay } \\
\text { based on } \\
\text { DNAzyme motor }\end{array}$ & yes & single signal & $1 \mathrm{pM}$ & 4 \\
\hline $\begin{array}{l}\text { fluorescent assay } \\
\text { based on signal } \\
\text { amplification }\end{array}$ & yes & single signal & $0.18 \mathrm{pM}$ & 5 \\
\hline $\begin{array}{l}\text { FRET assay based } \\
\text { on signal } \\
\text { amplification }\end{array}$ & yes & single signal & $2.27 \mathrm{fM}$ & 6 \\
\hline $\begin{array}{l}\text { HPLC-fluorescent } \\
\text { assay based on } \\
\text { recycling } \\
\text { amplification }\end{array}$ & yes & single signal & $0.26 \mathrm{fM}$ & 7 \\
\hline $\begin{array}{l}\text { fluorescent assay } \\
\text { based on split- } \\
\text { DNAzyme probe }\end{array}$ & yes & single signal & $10 \mathrm{pM}$ & 8 \\
\hline $\begin{array}{l}\text { colorimetric-PCR } \\
\text { assay based on } \\
\text { organic dye/single } \\
\text { enzyme }\end{array}$ & yes & single signal & $5 \mathrm{fM}$ & 9 \\
\hline
\end{tabular}




\begin{tabular}{|l|c|c|c|c|}
\hline photoluminescence & yes & & $4.56 \mathrm{pM}$ & 10 \\
(PL) based on & single signal & & \\
entropy-driven & & & $1 \mathrm{fM}$ & \\
\hline single-molecule in & no (individual & dual signal & & This \\
situ assay based on & molecule & (dual-color & & work \\
\hline dual-color probes & signal dots) & dots) & & \\
\hline
\end{tabular}

\section{References}

1. Zhang, K.; Yang, X.; Zhao, W.; Xu, M.; Xu, J.; Chen, H. Regulation and Imaging of Gene Expression via an RNA Interference Antagonistic Biomimetic Probe. Chem. Sci. 2017,8, 4973-4977.

2. Yang, X.; Zhang, K.; Zhang, T.; Xu, J.; Chen. H.; Reliable Förster Resonance Energy Transfer Probe Based on Structure-Switching DNA for Ratiometric Sensing of Telomerase in Living Cells. Anal. Chem. 2017, 89, 4216-4222. 
3. Yang, Y.; Huang, J.; Yang, X.; Quan, K.; Wang, H.; Ying, L.; Xie, N.; Ou, M.; Wang, K. FRET Nanoflares for Intracellular mRNA Detection: Avoiding False Positive Signals and Minimizing Effects of System Fluctuations. J. Am. Chem. Soc. 2015, 137, 8340-8343.

4. Peng, H.; Li, X.; Zhang, H.; Le, X. A MicroRNA-Initiated DNAzyme Motor Operating in Living Cells. Nat. Commun. 2017, 8,14378.

5. Li, L.; Feng, J.; Liu, H.Y.; Li, Q.L.; Tong, L.L.; Tang, B. Two-Color Imaging of MicroRNA with Enzyme-Free Signal Amplification via Hybridization Chain Reactions in Living Cells. Chem. Sci. 2016, 7, 1940-1945.

6. Xian, L.; Ge, H.; Xu, F.; Xu, N.; Fan, J.; Shao, K.; Peng, X. Intracellular MicroRNA Imaging Using Telomerase-Catalyzed FRET Ratioflares with Signal Amplification. Chem. Sci.2019, 10, 7111-7118.

7. Qi, T.; Song, C.; He, J.; Shen, W.; Kong, D.; Shi, H.; Tan, L.; Pan, R.; Tang, S.; and Lee, H.K. Highly Sensitive Detection of Multiple MicroRNAs by High-Performance Liquid Chromatography Coupled with Long and Short Probe-Based Recycling Amplification. Anal. Chem. 2020, 92, 5033-5040.

8. Wu, Y.; Huang, J.; Yang, X.; Yang, Y.; Quan, K.; Xie, N.; Li, J.; Ma, C.; Wang, K. Gold Nanoparticle Loaded Split-DNAzyme Probe for Amplified miRNA Detection in Living Cells. Anal. Chem. 2017, 89, 8377-8383. 
9. Dong, J.; Chen, G.; Wang, W.; Huang, X.; Peng, H.; Pu, Q.; Du, F.; Cui, X.; Deng, Y.; Tan. Z. Colorimetric PCR-Based microRNA Detection Method Based on Small Organic Dye and Single Enzyme. Anal.Chem. 2018, 90, 7107-7111.

10. He, X.; Zeng, T.; Li, Z.; Wang, G.; Ma, N. Catalytic Molecular Imaging of MicroRNA in Living Cells by DNA-Programmed Nanoparticle Disassembly. Angew. Chem., Int. Ed. 2016, 55, 3073-3076. 